\title{
A Review of Marine Safety Investigations Success Barriers
}

\author{
Salah Eldin Farid, and Magdy Ali Elashkar \\ Arab Academy for Science, Technology and Maritime Transport (AASTMT), Alexandria, Egypt
}

\begin{abstract}
This study reveals the most known barriers to successful marine safety investigations important role of effective marine accident investigation in the improvement of the maritime safety through prevention similar casualties from occurring in the future and explores the legal obligations of all parties under different international maritime conventions and codes. Since marine safety investigations results and recommendations are important for the maritime safety, so this paper determines, the shortage of application of the international regulations adopted by IMO related to maritime safety, and the shortage of legal measures to support safety at sea and protection or reduce marine pollution. This paper also aims to improve special measures for procedures of marine accident investigation and highlights the importance of identifying the liability and effective recommendations.
\end{abstract}

Key words: Accidents; incident, investigations; marine; safety; ships.

\section{Introduction}

The shipping industry is regarded as a very high-risk industry, this risky nature results in great losses and therefore makes it very necessary and essential for accident investigation to serve its purpose. It is widely recognized that there is need for accident investigation since it provides an avenue to learn lessons from and prevent future occurrences [1]. The main target of an accident investigation is usually to explain the course of events. An essential question is how the event could have happened. In most systems, especially in the case of large hazards, there are several safety features in place to prevent accidents from occurring. Accordingly, an essential complementary aim of any investigation should be to analyze how the safety system failed [2].

Marine safety investigations are typically conducted by or for government agencies or maritime companies, using largely legal logic that relies on the preponderance of evidence to determine the role of different factors in an accident's cause or causes. However, accidents in tightly coupled and complex

Corresponding author: Salah Eldin Farid, E-mail: salahfarid56@yahoo.com. systems should be considered as normal occurrences rather than abnormal. New kinds of accidents have developed in addition to those that were the focus of early accident investigations [1]. During marine safety investigations investigators trying their best to determine whether an accident would have occurred in the absence of specified events, and whether the events would have occurred in the absence of specific errors and/or system malfunctions. To determine if a mariner's error led to an accident, investigators must have sufficient evidence to allow a determination that without that error the accident would not have occurred. The ultimate purpose of a marine safety investigation is to advance maritime safety and protection of the marine environment, and identifying safety deficiencies through a systematic safety investigation of marine casualties and incidents, and then recommending or effecting change in the maritime system to correct these deficiencies. It is not the purpose of a safety investigation to determine liability or apportion blame.

These marine safety investigations should result in an increased awareness by all involved in the marine industry of the human, organizational, environmental, technical and external factors that may be involved in 
marine casualties and incidents. This awareness should lead to proactive measures by the maritime community which in turn should result in the saving of lives, ships, cargo and the protection of the marine environment, improvements to the lives of marine personnel, and safer shipping operations.

\section{Terminology of Marine Safety Investigation}

Always relying on the use of the terms of marine accident investigations approved by the International Maritime Organization by investigators or organizations concerned with marine accident investigations in order to develop an initial conception of the seriousness of this marine accident and we will review the most important of these terms:

\subsection{Causal Factor}

The casual factor means actions, omissions, events or conditions, without which:

- the marine casualty or marine incident would not have occurred;

- adverse consequences associated with the marine casualty or marine incident would probably not have occurred or have been as serious;

- iii another action, omission, event or condition, associated with an outcome in (i) or(ii)

- would probably not have occurred.

\subsection{Interested Party}

The interested party means an organization, or individual, who, as determined by the marine safety investigating State(s), has significant interests, rights or legitimate expectations with respect to the outcome of a marine safety investigation [3].

\subsection{Marine Incident}

Marine incident means an event, or sequence of events, other than a marine casualty, which has occurred directly in connection with the operations of a ship that endangered, or, if not corrected, would endanger the safety of the ship, its occupants or any other person or the environment. However, a marine incident does not include a deliberate act or omission, with the intention to cause harm to the safety of a ship, an individual or the environment [3].

\subsection{Marine Accident}

Marine accident means one or more than one marine undesired incident which results in personal injury, damage or loss. Accidents include loss of life or major injury to any person on board, the actual or presumed loss of a ship, her abandonment or material damage to her, collision or grounding, disablement, and also material damage caused by a ship. It is the duty of every master or skipper to examine any accident occurring to, or onboard, his ship [3].

\subsection{Marine Casualties}

Marine causality means an event, or a sequence of events, which has occurred directly in connection with the operations of a ship and has resulted in any of the following:

i-the death of, or serious injury to, a person; ii-the loss of a person from a ship; iii-the loss, presumed loss or abandonment of a ship; iv-material damage to a ship; $v$-the stranding or disabling of a ship, or the involvement of a ship in a collision; vi-material damage to marine infrastructure external to a ship, that could seriously endanger vii-the safety of the ship, another ship or an individual; ix-severe damage to the environment or the potential for severe damage to the environment,

$\mathrm{x}$ - brought about by the damage of a ship or ships.

However, a marine casualty does not include a deliberate act or omission, with the intention to cause harm to the safety of a ship, an individual or the environment [3].

\subsection{Event}

A happening caused by humans, automatically operating equipment/components, external events or 
the result of a natural phenomenon. Event descriptions typically include action verbs such as walked, turned, opened, said, radioed, discovered, decided, saw, etc. If negative (an error, failure or external factor), then the event may also be a causal factor, intermediate cause or root cause [4].

\section{Statistics of Marine Accidents and Marine Incidents}

The following tables give a summarize about the main statists in conjunction with the marine investigations. Table 1 explains the statistics of number of marine accidents since year 2007 until now and Table 2 shows the statistics of marine incident for the same period.

On the other side Fig. 1 describes the annual overview casualties and incidents, however Fig. 2 shows the annual overview casualties and incident 2018.

\section{A marine Safety Investigation}

Means an investigation or inquiry (however referred to by a State), into a marine casualty or marine incident, conducted with the objective of preventing marine casualties and marine incidents in the future. The investigation includes the collection of, and analysis of, evidence, the identification of causal factors and the making of safety recommendations as necessary.

Fig. 3 representation of Hollnagel's (1998) statement regarding accident investigations being conducted within an accident causation model's framework which will result in taxonomy and method that will support an accident investigation (Schröder, 2003). However, Schröder (2003) pointed out that it is the mandate of the investigation body that determines the focus of an investigation and as such the model to be used during the investigation [1].

Table 1 Statistics of Marine Accidents [5].

\begin{tabular}{|c|c|c|c|c|c|c|c|c|c|c|c|c|c|}
\hline Year & Collision & Contact & Grounding & Sinking & Flooding & Capsizing & Fire & Explosion & $\begin{array}{l}\text { Vessel } \\
\text { missing }\end{array}$ & $\begin{array}{l}\text { Facility } \\
\text { damage }\end{array}$ & $\begin{array}{l}\text { Fatality/ } \\
\text { Injury }\end{array}$ & Others & Total \\
\hline 2019 & 178 & 76 & 156 & 11 & 21 & 53 & 28 & 0 & 0 & 17 & 119 & 0 & 659 \\
\hline 2018 & 243 & 87 & 172 & 21 & 26 & 51 & 24 & 2 & 0 & 23 & 179 & 0 & 828 \\
\hline 2017 & 200 & 96 & 181 & 14 & 22 & 55 & 27 & 3 & 0 & 23 & 143 & 0 & 764 \\
\hline 2016 & 217 & 94 & 163 & 5 & 19 & 46 & 26 & 3 & 0 & 21 & 144 & 0 & 738 \\
\hline 2015 & 244 & 102 & 202 & 5 & 12 & 56 & 38 & 3 & 0 & 20 & 122 & 1 & 805 \\
\hline 2014 & 265 & 116 & 213 & 7 & 11 & 61 & 35 & 1 & 0 & 37 & 150 & 3 & 899 \\
\hline 2013 & 264 & 145 & 210 & 10 & 25 & 49 & 33 & 2 & 0 & 38 & 163 & 2 & 941 \\
\hline 2012 & 246 & 132 & 264 & 5 & 21 & 55 & 44 & 2 & 0 & 34 & 155 & 0 & 958 \\
\hline 2011 & 282 & 145 & 264 & 12 & 18 & 56 & 32 & 1 & 0 & 23 & 142 & 1 & 977 \\
\hline 2010 & 356 & 180 & 369 & 15 & 18 & 50 & 35 & 2 & 0 & 26 & 146 & 0 & 1197 \\
\hline 2009 & 325 & 174 & 431 & 16 & 19 & 58 & 42 & 3 & 0 & 38 & 217 & 2 & 1325 \\
\hline 2008 & 181 & 101 & 255 & 12 & 4 & 28 & 15 & 3 & 0 & 30 & 61 & 0 & 690 \\
\hline 2007 & 0 & 1 & 2 & 0 & 0 & 0 & 0 & 0 & 0 & 0 & 0 & 0 & 3 \\
\hline
\end{tabular}


Table 2 Statistics of Marine Incidents [5].

Number of Marine Incidents by Year as of October 31, 2019

\begin{tabular}{|c|c|c|c|c|c|c|c|c|}
\hline \multirow[t]{2}{*}{ Year } & \multicolumn{3}{|c|}{ Loss of control } & \multirow[t]{2}{*}{ Stranded } & \multirow{2}{*}{$\begin{array}{l}\text { Safety } \\
\text { obstruction }\end{array}$} & \multirow{2}{*}{$\begin{array}{l}\text { Navigation } \\
\text { obstruction }\end{array}$} & \multirow[t]{2}{*}{ Others } & \multirow[t]{2}{*}{ Total } \\
\hline & $\begin{array}{l}\text { Machinery } / \\
\text { Propulsion failure }\end{array}$ & Listing & $\begin{array}{l}\text { Insufficient fuel/ } \\
\text { lube oil/ } \\
\text { cooling water }\end{array}$ & & & & & \\
\hline 2019 & 140 & 1 & 11 & 12 & 0 & 15 & 0 & 179 \\
\hline 2018 & 104 & 0 & 3 & 10 & 0 & 10 & 0 & 127 \\
\hline 2017 & 112 & 2 & 1 & 4 & 3 & 20 & 0 & 142 \\
\hline 2016 & 77 & 1 & 7 & 6 & 6 & 14 & 0 & 111 \\
\hline 2015 & 82 & 0 & 3 & 4 & 4 & 12 & 0 & 105 \\
\hline 2014 & 89 & 1 & 2 & 15 & 0 & 24 & 0 & 131 \\
\hline 2013 & 98 & 2 & 6 & 7 & 3 & 25 & 0 & 141 \\
\hline 2012 & 108 & 0 & 5 & 5 & 4 & 35 & 0 & 157 \\
\hline 2011 & 96 & 1 & 6 & 10 & 1 & 35 & 0 & 149 \\
\hline 2010 & 80 & 0 & 3 & 16 & 0 & 38 & 0 & 137 \\
\hline 2009 & 102 & 0 & 3 & 33 & 0 & 59 & 0 & 197 \\
\hline 2008 & 53 & 1 & 0 & 34 & 8 & 87 & 0 & 183 \\
\hline 2007 & 0 & 0 & 0 & 0 & 0 & 0 & 0 & 0 \\
\hline
\end{tabular}

\section{KEY FIGURES FOR 2011-2018}

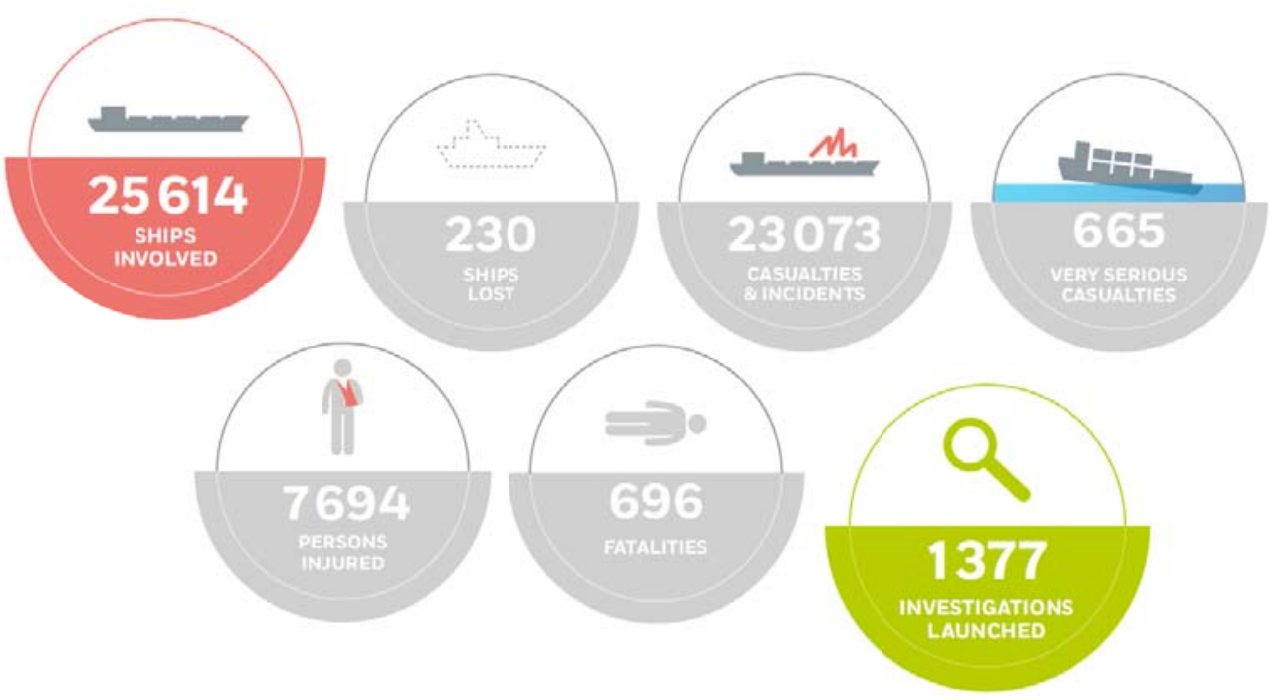

Fig. 1 Annual overview casualties and incident 2019 [6]. 


\section{KEY FIGURES FOR 2011-2017}
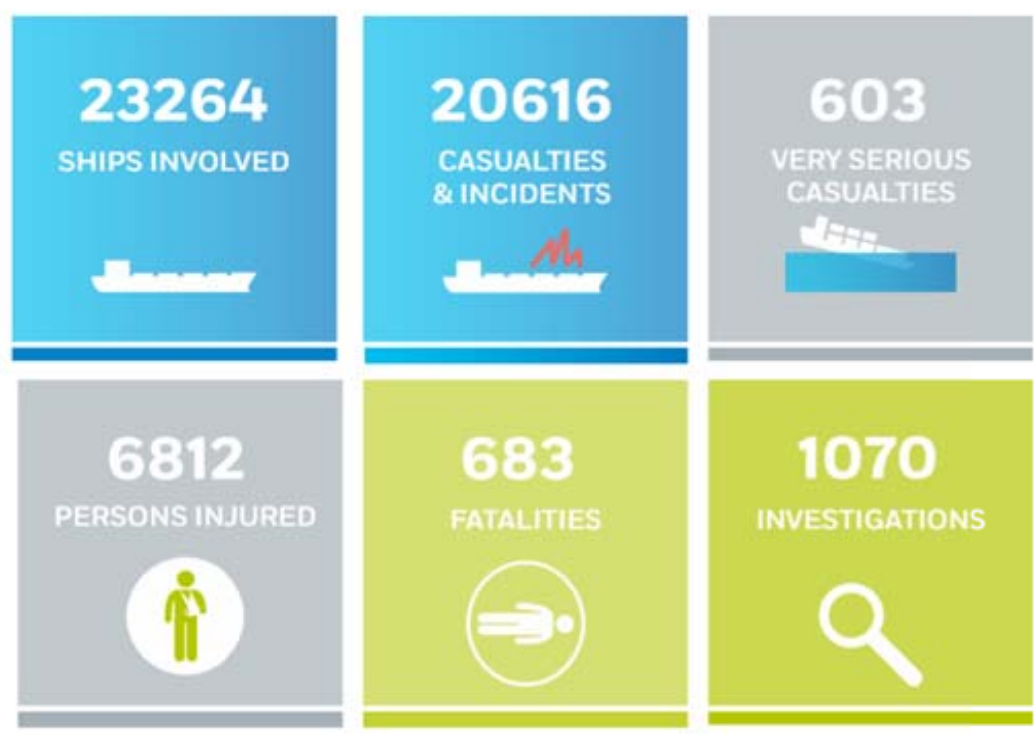

Fig. 2 Annual overview casualties and incident 2018 [6].

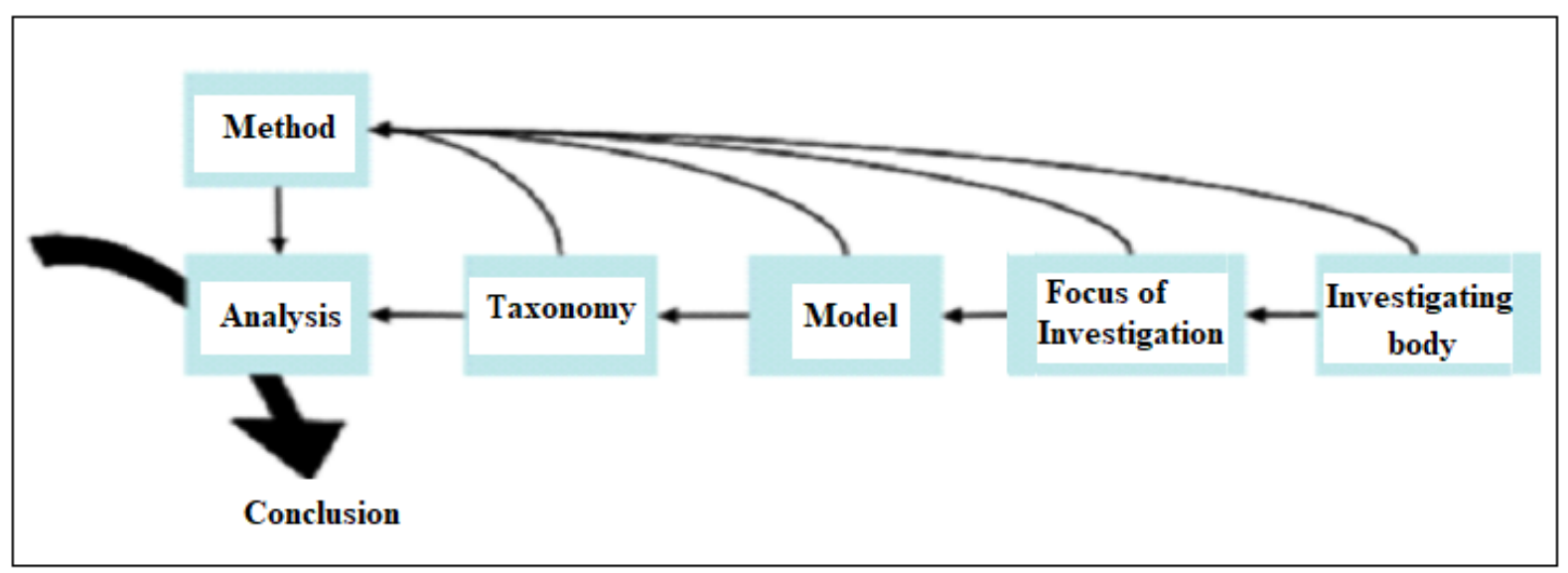

Fig. 3 Framework for casualty investigation [1].

\subsection{Conventions and Guidelines Regulate Marine Safety Investigations}

The obligations to conduct marine accident investigation and its requirements were mentioned in regulations and conventions such as:

(1) (UNCLOS 82) where stated that "it is the responsibility of every Flag State to conduct investigation in any casualty that occurs on board a ship flying the flag of the State.

(2) (SOLAS74) as amended Reg $1 / 21$ states that "Each Administration undertakes to conduct an investigation of any casualty occurring to any of its ships subject to the provisions of the present convention when it judges that such an investigation may assist in determining what changes in the present regulations might be desirable."

(3) (MARPOL 73/78) as amended article 12 states that Each Administration undertakes to conduct an investigation of any casualty occurring to any of its ships subject to the provisions of the regulations if such casualty has produced a major deleterious upon the marine environment.

(4) International load line conventions 1966 Article 
23 of states Each Contracting Government undertakes to supply the Organization with the pertinent information concerning the findings of such investigations.

(5) Casualty Investigation Code 2008 Chapter 6 states "A marine safety investigation shall be conducted into every very serious casualty".

(6) The Maritime Laboure Convention 2006 standard 4.3 para 5 states the competent authority shall ensure that: occupational accidents, injuries and diseases are adequately reported and comprehensive statistics of such accidents and diseases are kept, analyzed and published.

\subsection{Levels of Investigation}

Each IMO Member State shall ensure a safety investigation is carried out into the causal factors of all very serious casualties involving ships flying its flag, irrespective of the location of the casualty, also the safety investigation may be conducted by the Flag State or by another Substantially Interested State by mutual agreement between them [7], and it's divided to:

(a) Flag State investigation: each Administration undertakes to conduct an investigation into any casualty occurring to ships under its flag.

(b) The Company with Master and safety officer investigation: The safety management system should include procedures ensuring that non-conformities, accidents and hazardous situations are reported to the Company, investigated and analyzed with the objective of improving safety and pollution prevention.

\subsection{Timing of the Investigation}

An investigation should be carried out as soon as possible after an occurrence. The quality of evidence, particularly that relying on the accuracy of human recollection, can deteriorate rapidly with time, delayed investigations are usually not as conclusive as those performed promptly [8].

\subsection{Extent of Investigation}

The extent of any safety investigation can be divided into five areas people, environment, equipment processes and procedures, organization and external influences, Marine casualty or incident safety investigations should therefore be seen as a means of identifying not only the accident events, but also safety deficiencies in the overall management of the operation from policy through to its implementation, as well as in regulation, survey and inspection. For this reason, safety investigations should be broad enough to meet these overriding criteria [9].

\section{Benefits of Conducting Marine Safety Investigations}

The objective of any marine casualty investigation is to prevent such casualties in the future. Investigations identify the circumstances of the casualty under investigation and establish the causes and contributing factors, by gathering and analyzing information and drawing conclusions [10]. Ideally, it is not the purpose of such investigations to determine liability, or apportion blame only but also to improve the following benefits, to find the cause of the event and prevent the recurrence of similar events in the future, to Comply with legal requirements, to estimate the cost of the event, to determine compliance with applicable legislation, and compensating workers' complaints.

\section{Marine Safety Investigations Procedures}

An appropriate strategy must be devised for maritime investigation procedures, by setting the appropriate time to preview the accident site to collect theoretical and practical evidence and fact-finding for analysis to reach the direct and hidden causes that led to the accident.

Therefore, the final report is prepared for publication to generalize the benefit of the results of this investigation. The report's results are turn into 
Table 3 Marine Accident Investigations (Safety digest lessons from Marine Accident Reports No 1/2019).

\begin{tabular}{|c|c|c|c|c|c|}
\hline $\begin{array}{l}\text { Date of } \\
\text { Occurrence }\end{array}$ & $\begin{array}{l}\text { Name of } \\
\text { Vessel }\end{array}$ & $\begin{array}{l}\text { Type of } \\
\text { Vessel }\end{array}$ & Flag & Size & $\begin{array}{l}\text { Type of } \\
\text { Occurrence }\end{array}$ \\
\hline 29/09/2018 & $\begin{array}{l}\text { Red Falcon/ } \\
\text { Phoenix }\end{array}$ & $\begin{array}{l}\text { Passenger ro-ro cargo } \\
\text { Motor cruiser }\end{array}$ & UK & $\begin{array}{l}4128 \mathrm{gt} \\
\text { Unknown }\end{array}$ & Collision \\
\hline $21 / 10 / 2018$ & Red Falcon/Greylag & $\begin{array}{l}\text { Passenger ro-ro cargo } \\
\text { Motor cruiser }\end{array}$ & UK & $\begin{array}{l}\text { 4128gt } \\
\text { Unknown }\end{array}$ & Collision \\
\hline 06/11/2018 & $\begin{array}{l}\text { Stena Superfast VII/ } \\
\text { Royal Navy submarine }\end{array}$ & $\begin{array}{l}\text { Passenger ro-ro cargo } \\
\text { Submarine }\end{array}$ & $\begin{array}{l}\text { UK } \\
\text { UK }\end{array}$ & $\begin{array}{l}30285 \mathrm{gt} \\
\text { Unknown }\end{array}$ & Hazardous incident \\
\hline $14 / 12 / 2018$ & Wight Sky & Passenger ro-ro cargo & UK & $2546 \mathrm{gt}$ & Fire \\
\hline $15 / 12 / 2018$ & Thea II/Svitzer Josephine & $\begin{array}{l}\text { General cargo } \\
\text { Tug }\end{array}$ & $\begin{array}{l}\text { Cyprus } \\
\text { UK }\end{array}$ & $\begin{array}{l}2899 \mathrm{gt} \\
364 \mathrm{gt}\end{array}$ & Groundings \\
\hline $17 / 12 / 2018$ & Seatruck Pace & Ro-ro cargo & Cyprus & $14759 \mathrm{gt}$ & Accident to person \\
\hline $18 / 12 / 2018$ & Kuzma Minin & Bulk carrier & Russia & $16257 \mathrm{gt}$ & Grounding \\
\hline $18 / 12 / 2018$ & European Causeway & Passenger ro-ro cargo & Bahamas & $20646 \mathrm{gt}$ & Cargo shift \\
\hline 17/01/2019 & Tiger One & Recreational yacht & UK & Unknown & Contact \\
\hline 27/01/2019 & Millgarth & Tug & UK & $374 \mathrm{gt}$ & Accident to person \\
\hline 03/02/2019 & Investor & Fishing vessel |Potter & UK & $8.92 \mathrm{gt}$ & Capsize | Foundering \\
\hline 28/02/2019 & Cherry Sand & Dredger & UK & $1081 \mathrm{gt}$ & Accident to person \\
\hline
\end{tabular}

applying recommendations. By improving the link between the accident investigation and the risk analysis processes [11]. The report has to be made at this stage as IMO MSC-MEPC.3/Circ.4 requires that the final version of the marine safety investigation together with particular marine casualty data to be entered into the Global Integrated Shipping Information System (GISIS) marine casualties and incidents module. Finally, there will be consultation for rectification of particular matters on the report and then a follow up on safety recommendations for positive reinforcement by making the recommendations public.

\section{Marine Safety Investigations Success Barriers}

The main target of an accident investigation is usually used to explain the course of events occurring. An essential question is how the event could have happened [2]. In order reach to the accurate answer many barriers that facing success of maritime accident investigations will be reviewed to avoid the negative impact of them, as follows:

(1) The company always in reactive mode rather than proactive mode:

Unfortunately, in many cases of maritime incidents the company reacts to incidents rather than planning ahead, this lead to lose one of the main goals of the marine safety investigations which is to prevent the re-occurrence of the incidents.

(2) The company insisting on blaming someone:

One of the causes of investigating failed that management insists on blaming persons instead of figuring out how to prevent the accidents from reoccurring. This action will eliminate efforts to understand and fixing the real causes.

(3) Unwilling to Critique Management Systems:

This happens when managers are not willing to accept that they could contribute in any way to a deficiency in the organization.

(4) Investigations are only done on major incidents:

Personnel will not be ready to do a good job on the big incidents if they do not practice with the smaller incidents.

(5) Recommendations are not implemented:

When recommendations are not followed till completion or there are no rewards/punishments for not implementing those recommendations, in some cases, are not implemented which leads to wasting of the investigation effort.

(6) Unqualified investigator:

Marine safety investigation should be carried out by 
qualified investigator who is well trained for investigations procedures, aware of the local and international laws related to the marine safety investigations, in possession of the proper tools needed for the investigations, able to conduct interviews with the witnesses, able to analyze the causes and provide the recommendations, know how to fill-up the investigation form.

(7) Difficulties to access the accident scene:

This can happen due to the nature of the accident such as fire or sinking of the vessel.

(8) Lack of witnesses:

Sometimes it's impossible to find witnesses who actually witnessed the accident, who is impartial person or who is not fit for interview due physical state.

(9) Unreasonable delays in investigations start:

The time between the accident and the start of the investigation should be minimized as possible, to giving more chance to observe the circumstances of accident as they are.

(10) Following nonlogical investigations steps:

Failure to follow technical steps to conduct marine incident investigations according to their logical sequence as per the circumstances of the incident.

(11) Reliance on unproven assumptions:

A miss lead can be happened when the investigator follows or rely on unproven assumption as a consequence, the results, analysis and recommendation will be destined to fail.

(12) Poor quality of the final reports:

Some reports provide little help in identifying safety improvements. The data collected may be incomplete (facts missing, unclear sequence of events, superficial description of the context of the event) [12].

\section{Recommendations and Safety Actions}

After the completion of study, the different features regarding the marine investigation's statistics, causes, barriers, and the related conventions, the following aspects could be concluded:

(1) The ultimate goal of a marine safety investigation is to advance maritime safety and protection of the marine environment. In the context of these Guidelines, this goal is achieved by identifying safety deficiencies through a systematic investigation of marine casualties and incidents, and then recommending or effecting change in the maritime system to correct these deficiencies.

(2) In a report that clearly lays out the facts relevant to the occurrence, and then logically analyses those facts to draw reasoned conclusions including those relating to human factors, the required safety action may appear self-evident to the reader.

(3) Recommended safety action in whatever form should clearly identify what needs to be done, who or what organization is responsible for effecting change, and, where possible, the urgency for completion of the change.

(4) Safety recommendations shall in no case create a presumption of blame or liability [13].

(5) Accident rates, analyses of risks and hazards, investigations of past accidents and near misses, and analyses of organizational characteristics such as safety culture or safety climate all provide sources of information about different aspects of safety. In the safety literature, a distinction is commonly drawn between individual accidents and organizational accidents [14].

(6) Completing investigations to focus the reasons for accidents adrift.

(7) Distribute reports that incorporate suggestions on enhancing safety adrift and progress made.

(8) Expanding familiarity with how marine accidents happen.

(9) Enhancing national and global co-operation in marine accident investigation [13].

(10) Communicating information about the occurrence provides valuable learning opportunities to members of the industry, regardless of whether or not they were involved in the occurrence [15]. 
(11) Improving the link between the accident investigation and the risk analysis processes [11].

(12) Avoid Conflicts of interest, the objective of a safety investigation should be the prevention of

(13) accidents and it is recognized that whether or not one is in consensus, the only way to achieve this, is through an independent investigation, which is unbiased and based on facts and honest conclusions [16].

(14) As we have seen, incidents and accident today are not the consequence of major dangers, but rather the result of chains of minor lapses. The first step toward an improvement is therefore to gather all information about what is happening within the company - to collect information on every kind of hazard or safety-related misconduct [17].

\section{Conclusion}

The present paper discussed the different marine investigations, presented the latest statistics regarding those investigations. In addition, the barriers of successes were explained. The following facts can be pointed out:

- Company should reward the implementation of preventative and corrective actions at all levels in the organization, including management, whether successful or not in eliminating the cause(s).

- Company should focus on the management system, not blaming individuals. This will lead to the long-term solution of the organization's problems.

- Company should focus on investigating near misses same as large disasters and to establish a minimum reporting goal of 10 near misses for example for every loss incident and hold management and employees accountable for reporting near misses and meeting this goal.

- Company should assign someone for tracking recommendations to completion, to review the implementation status periodically.

- Company should reward individuals and departments for implementing recommendations and discipline those who do not implement them.

- Management should review the recommendations from an overall vessel and organizational perspective to ensure that each recommendation will have a high benefit across the fleet.

- Management should ensure that the recommendations are implemented in a timely manner by establishing a schedule and assigning resources to complete them.

- Company should ensure that affected personnel receive necessary information/training about the recommendations. Individuals affected by implementing recommendations need to be properly trained regarding the changes and effects resulting from implementation of the recommendations.

- Management must ensure that proper documentation of the resolution of each recommendation is performed. Resolution can include accepting the recommendation, accepting a modification or similar alternative recommendation, deferring the implementation until after further evaluation or rejecting the recommendation for cause.

\section{Reference}

[1] Fatoumatta Cassama (2105). "A Study on Marine Accident Causation Models Employed by A Study on Marine Accident Causation Models Employed by Marine Casualty Investigators." Thesis of World Maritime University, Sweden.

[2] Lars Harms-Ringdahl (2009). "Analysis of Safety Functions and Barriers in Accidents." Journal of Safety Science 47: 353-363.

[3] IMO (2008). "Code of the International Standards and Recommended Practices for a Safety Investigation into a Marine Casualty or Marine Incident (Casualty Investigation Code 2008)."

[4] ABS (2014). "Guidance Notes on the Investigation of Marine Incidents."

[5] https://www.mlit.go.jp/jtsb/statistics_mar.html.

[6] EMSA (2019). “Annual Review of Marine Causalities and Incidents 2019." Technical report, European Maritime Safety Agency, accessed 02-10-2019. http://www.emsa.europa.eu/news-a-press-centre/externalnews/download/5854/3734/23.html.

[7] MIIF (2017). The Marine Accident Investigators' 
International Forum (Maiif investigation Manual), Technical report, accessed 01-10-2019. https://maiif.org/wp-content/uploads/2017/08/MAIIF-Ma nual-2014.pdf.

[8] IMO (2001). "Resolution A.884(21) Amendments to the Code for the Investigation of Marine Casualties and Incidents."

[9] IMO (2013). "Resolution A.1075(28) Guidelines to Assist Investigators in the Implementation of the Casualty Investigation Code."

[10] Kuehmayer J. R. (2008). "Marine Accident and Casualty Investigation Boards." Technical report, accessed 15-11-2019. http://www.amem.at/pdf/AMEM_Marine_Accidents.pdf.

[11] "Ludwig Benner Jr Standardizing Safety Investigation Inputs to Reduce." 45th ESReDA Seminar on Dynamic Learning from Incidents and Accidents, Porto Portuga.

[12] ESReDA (2015). "Barriers to learning from incidents and accidents-European Safety Reliability and Data Association (ESReDA)." Project Group Dynamic Learning as the Follow-up from Accident Investigations. https://www.esreda.org/wp-content/uploads/2016/03/ESR
eDA-barriers-learning-accidents-1.pdf. Accessed 22-11-2019.

[13] Marine Accident Investigation Branch (MAIB) (2019). Safety Digest Lessons from Marine Accident Reports No 1/2019. https://assets.publishing.service.gov.uk/governm ent/uploads/system/uploads/attachment_data/file/790251/ 2019-SD1-MAIBSafetyDigest.pdf. Access 12-11-2019.

[14] Antonio's Deligiannis (2016). "Risk Analysis of Marine Accidents Derived from Inspection Mistakes." Diploma thesis, National Technical University of Athens.

[15] Australian Transport Safety Bureau - Analysis, Causality and Proof in Safety Investigations - Aviation Research and Analysis Report -AR-2007-053.

[16] Kevin Thomas Ghirxi (2003). "Implementation of the Code for the Investigation of Marine Casualties and Incidents: A Critical Analysis." World Maritime University, Sweden.

[17] Freibott B. (2013). "Sustainable Safety Management: Incident Management as a Cornerstone for a Successful Safety Culture." WIT Transactions on the Built Environment 134. 